Title

Tension pneumopericardium following blunt chest trauma

Running title

Tension penumopericardium

Authors

Tom Sutherland MBBS(hons) MMed Grad Dip Clin Ed FRANZCR 1,2

Sarah Parsons BMedSci(Hons) MBBS(Hons) DipForPath DipLaw FRCPA

Master Pathologica Cardiovasculare 3, 4

Stephen Cordner AM MA MB BS BMedSc DipCrim DMJ FRCPath FRCPA 3, 4

Chris O’Donnell MBBS, MMed, Grad Dip For Med FRANZCR 3,4

1. St Vincent's Hospital, Medical Imaging Department, 41 Victoria Pde Fitzroy 3065

2. University of Melbourne, Faculty of Medicine, Dentistry and Health Science, Parkville

3. Victorian Institute of Forensic Medicine, 65 Kavanagh St Southbank 3006

4. Monash University, Department of Forensic Medicine

Corresponding Author

Tom.sutherland@svha.org.au

Key Words

Post Mortem CT

Tension pneumopericardium

Trauma

This is the author manuscript accepted for publication and has undergone full peer review but has not been through the copyediting, typesetting, pagination and proofreading process, which may lead to differences between this version and the Version of Record. Please cite this article as doi: 10.1111/1754-9485.12890

This article is protected by copyright. All rights reserved 
Article type: Radiology Letter to the Editor (ARA)

\section{Tension pneumopericardium following blunt chest trauma}

Patients suffering blunt chest trauma have high mortality rates due to a wide variety of injuries including pulmonary laceration, tracheobronchial injury, vascular and cardiac injury and the development of ectopic air such as pneumothorax $(1,2)$. By comparison to pneumothorax, pneumopericardium is uncommon, and cases of tension pneumopericardium are rare $(3,4)$. Computed tomography (CT) plays an important role in the assessment of patients with blunt chest trauma, guiding therapeutic decision-making and prognosis (5). In deceased persons, CT also has a significant role in detecting otherwise invisible ectopic gas, possibly as a prelude to autopsy, or to supplement an external post mortem examination only.

A 34 year old female fell three floors into an atrium of a shopping centre landing on her legs which sustained multiple fractures. The fall was witnessed by a registered nurse who, after a preliminary survey, commenced CPR following which a laryngeal mask was inserted by paramedics. There was no return of spontaneous respiration and death was pronounced at the scene. Post-mortem CT (PMCT) demonstrated a large right sided pneumothorax, tiny left pneumothorax, small pneumomediastinum and large pneumopericardium (figure 1) with up to $33 \mathrm{~mm}$ separation between the pericardium and heart. Multiple pulmonary lacerations were present bilaterally. Gas was present around the level of the pulmonary veins on the right and the cardiac chambers were small.

Pneumopericardium is defined as air within the pericardial cavity while a tension pneumopericardium is when the pressure of the air impedes cardiac contraction and subsequently cardiac output. The classically described signs and symptoms of tension pneumopericardium include pulsus paradoxicus , tachycardia, reduced cardiac output with increased central venous pressure, 
muffled heart sounds and low voltage ECG traces although many of these may also be produced by coexisting injuries.

A number of mechanisms can lead to injury in blunt chest trauma including increased thoracic pressures and shearing forces secondary to thoracic compression, rapid deceleration and direct impact. These forces lead to a number of potential different pathways for a pneumopericardium to develop. One mechanism is alveolar disruption, with gas then dissecting along pulmonary arteries and veins, reaching and entering the pericardial reflections producing pneumopericardium. Another potential conduit is a pericardial tear leading to a direct communication with the pleural space or a disrupted tracheobronchial tree (4). The pericarinal trachea is in close proximity to the transverse sinus of the pericardium and could potentially be a site of direct communication with the majority of bronchial injuries occurring in the pericarinal proximal bronchus (5). It is likely that the mechanism in our cases was either a disrupted tracheobronchial tree or a direct tear communicating between the pleura and pericardium, with the air being introduced during resuscitation and subsequently impeding those efforts, rather than as a primary cause of death. Unfortunately an autopsy was not performed to confirm the site of injury.

Tension pneumopericardium has been defined as occurring when the cardiac size reduces on serial imaging producing the 'small heart sign' and causing marked clinical deterioration. CT is more sensitive and specific for the detection of pneumopericardium, and when compression and flattening of the heart occurs, especially the right ventricle anteriorly, tension pneumopericardium should be diagnosed (5). In clinical series many patients are receiving positive pressure ventilation, and radiologists working with trauma patients should be aware of this uncommon but critical complication. 
1. Shorr RM, Crittenden M, Indeck M, Hartunian SL, Rodriguez A. Blunt thoracic trauma. Analysis of 515 patients. Ann Surg. 1987;206:200-205.

2. Veysi VT, Nikolaou VS, Paliobeis C, Efstathopoulos N, Giannoudis PV. Prevalence of chest trauma, associated injuries and mortality: a level I trauma centre experience. Int Orthop. 2009;33:1425-1433. doi: 1410.1007/s0026400009-00746-00269. Epub 02009 Mar 00266.

3. Shorr RM, Mirvis SE, Indeck MC. Tension pneumopericardium in blunt chest trauma. J Trauma. 1987;27:1078-1082.

4. Capizzi PJ, Martin M, Bannon MP. Tension pneumopericardium following blunt injury. J Trauma. 1995;39:775-780.

5. Lomoschitz FM, Eisenhuber E, Linnau KF, Peloschek P, Schoder M, Bankier AA. Imaging of chest trauma: radiological patterns of injury and diagnostic algorithms. Eur J Radiol. 2003;48:61-70.

Figure Legends

Figure 1a

Axial post mortem CT demonstrates a right sided pneumothorax, surgical emphysema, pulmonary laceration in the lingula and a large volume of gas within the pericardial sac. The heart is small secondary to collapse of the cardiac chambers from the raised pericardial pressures.

Figure $1 b$

Coronal post mortem CT in the same patient demonstrates that the pericardial gas produces distension of the pericardial sac with secondary cardiac compression. Note the bilateral pulmonary lacerations.

This article is protected by copyright. All rights reserved 

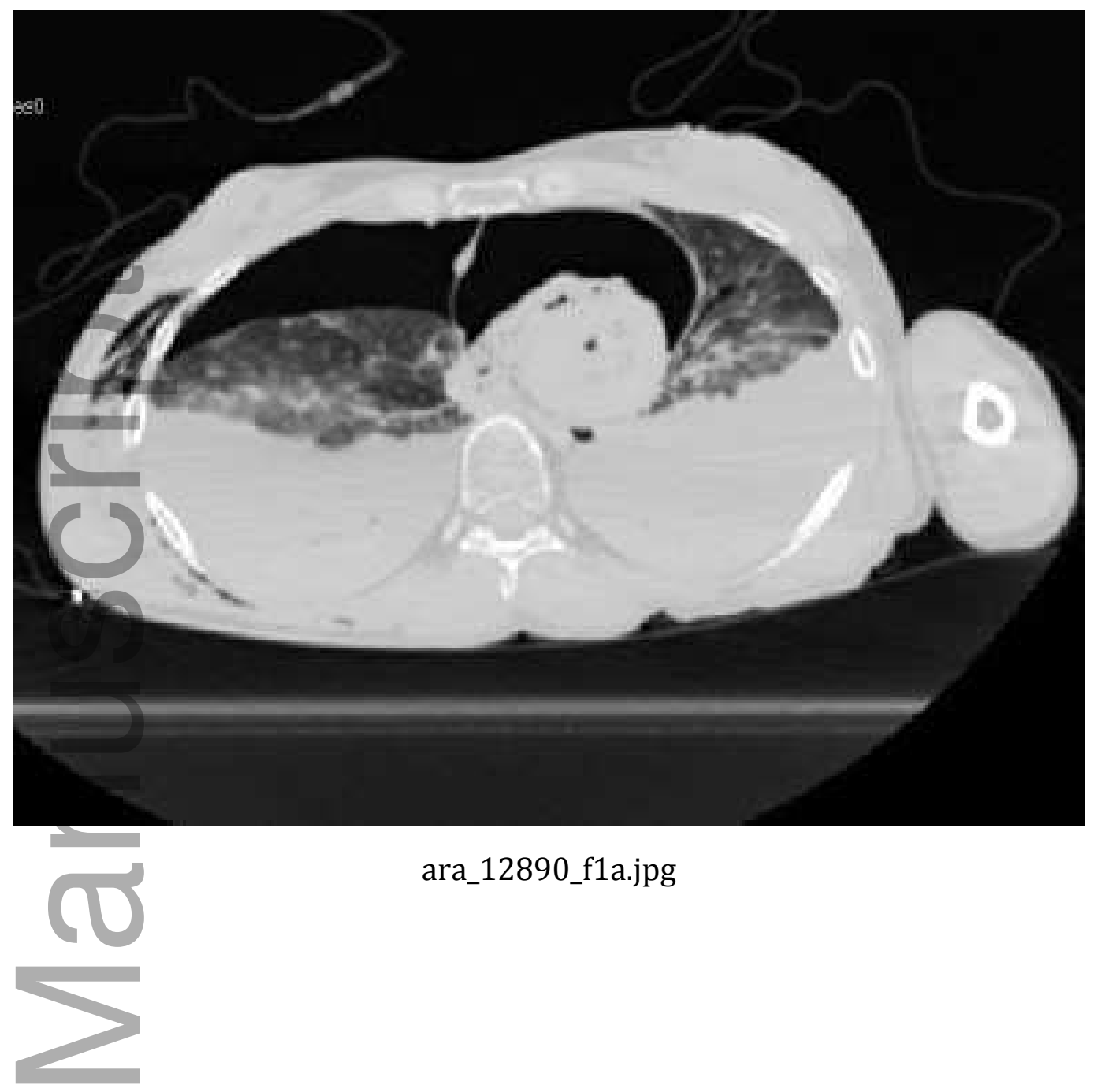

ara_12890_f1a.jpg

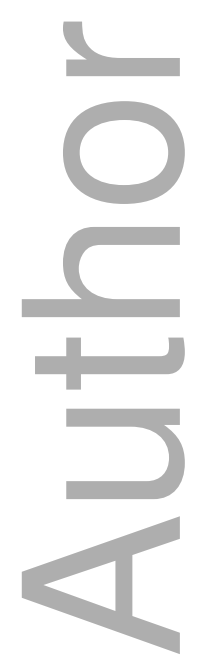



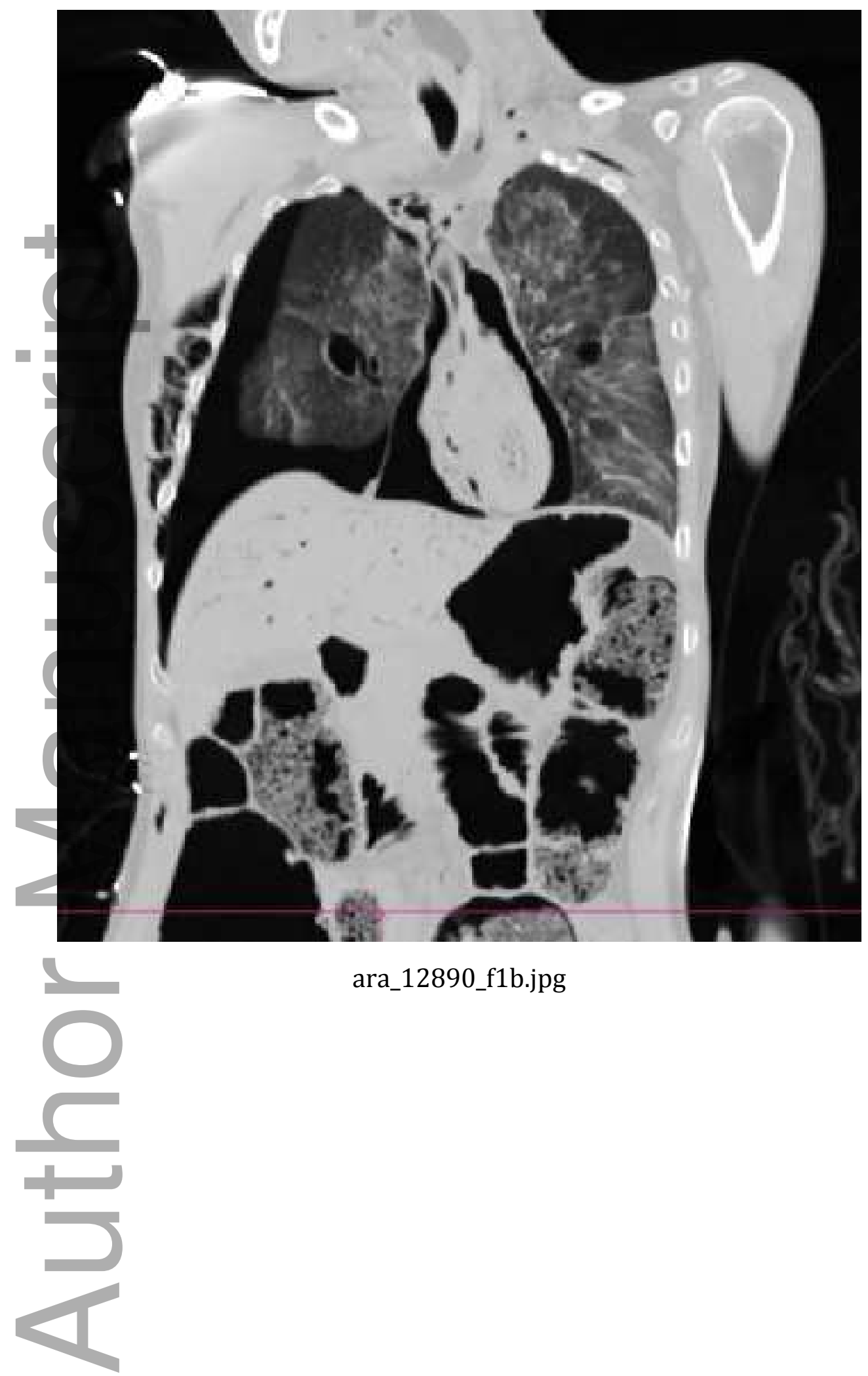


\section{University Library}

\section{- M M N E R VA A gateway to Melbourne's research publications}

Minerva Access is the Institutional Repository of The University of Melbourne

Author/s:

Sutherland, T;Parsons, S;Cordner, S;O'Donnell, C

Title:

Tension pneumopericardium following blunt chest trauma

Date:

2019-06-01

Citation:

Sutherland, T., Parsons, S., Cordner, S. \& O'Donnell, C. (2019). Tension pneumopericardium following blunt chest trauma. JOURNAL OF MEDICAL IMAGING AND RADIATION ONCOLOGY, 63 (3), pp.358-359. https://doi.org/10.1111/1754-9485.12890.

Persistent Link:

http://hdl.handle.net/11343/285763 